\title{
CORRECTION
}

View Article Online

View Journal I View Issue

D) Check for updates

Cite this: Soft Matter, 2020,

16,6683

DOI: $10.1039 / \mathrm{d} 0 \mathrm{sm} 90136 \mathrm{a}$

rsc.li/soft-matter-journal

\section{Correction: Anomalous and heterogeneous DNA transport in biomimetic cytoskeleton networks}

\author{
Jonathan Garamella, Kathryn Regan, Gina Aguirre, Ryan J. McGorty and \\ Rae M. Robertson-Anderson* \\ Correction for 'Anomalous and heterogeneous DNA transport in biomimetic cytoskeleton networks' by \\ Jonathan Garamella et al., Soft Matter, 2020, DOI: 10.1039/d0sm00544d.
}

The authors would like to add the following funding support for this work: This work was supported by NIH-NIGMS Award \# R15GM123420 to R. M. R.-A. and R. M., AFOSR Award \# FA9550-17-1-0249 to R. M. R.-A., ACS PRF Award \# 57326-UNI10 to R. M., and NSF Award CBET-1603925 to R. M. R.-A.

The Royal Society of Chemistry apologises for these errors and any consequent inconvenience to authors and readers. 